\title{
Despliegue estatal y fondos de pensiones en Venezuela
}

\section{Díaz, Luis Eduardo*}

\section{Resumen}

Se observa en el presente documento que están dadas las condiciones para que ocurra un desplazamiento de la seguridad social al mercado financiero de forma distinta a lo sostenido por el discurso politico. En segundo término, la instalación de un mercado sobre otro; el de pensiones sobre el laboral, tiene deficiencias, fallas y carencias de afiliados. Las deficiencias pueden evitarse con una adecuada supervisión y regulación (escaso ahorro voluntario y escasa información) en tanto que las fallas se aprecian como estructurales (monopolios/ comisiones y riesgos de mercado). Se contribuye a clarificar el papel del sector privado en la seguridad social y se propone el programa público por objetivos y funciones asignándoselas a diferentes gerencias. Por último, se analizan las posturas ideológicas y las diferencias entre la solidaridad y la capitalización individual, señalando el posible modelo a adoptar.

Palabras clave: Seguridad social, solidaridad, capitalización individual, pensiones, jubilaciones.

\section{State Development and Pension Funds in Venezuela}

\section{Abstract}

This paper points out that conditions are ripe for the transferal of social security functions from the state to the financial market in ways that differ from those explained and proposed in political discourse up until now. Secondly, the installation of one market over another; pensions over labor wages, is deficient anderroneous, and lacks affiliates. The deficiencies can be avoided with adequate supervision and regulation (due to lack of voluntary savings and lack of information), but the errors seem to be structural (monopolies, commissions and market risks). This paper helps to clarify the role of the public sector in social security and proposes a public program according to objectives and functions, assigning them to different agencies. Finaliy it analyzes ideological aspects and the differences between solidarity and individual capitalization, pointing out a possible model that could be adopted.

Key words: Social security, solidarity, individual capitalization, pensions, retirement funds.

Recibido: 01-01-15. Aceptado: 01-06-05

* Investigador del Centro de Investigaciones y Estudios Laborales y Disciplinas Afines (LUZ). Apartado Postal 10.432. E-mail: iuisediaz telcel.net.ve. 


\section{Introducción}

El presente trabajo aborda críticamente las modificaciones en el gobierno de la seguridad social, tomando como referencia los ensayos de la comisión presidencial para su reforma y los antecedentes legislativos de 1998, formulando los objetivos y funciones del programa por gerencia, destacando la importancia del recurso humano para producir los cambios que propendan a la ampliación de la cobertura.

El argumento que se defiende es el de una rectoría social, mas que financiera, en razón de la insuficiencia de competencias que las finanzas públicas poseen para asumir responsabilidades sociales ineludibles. Pero se advierte que la intervención no impide la participación priva$\mathrm{da}$ aspecto que es crucial en el debate de reforma, aclarando hasta dónde y cómo se desarrollan ambas modalidades y cuáles son las deficiencias, fallas y corresponsabilidades en el nuevo sistema.

La segunda parte se dedica al régimen financiero, presentando diferentes alternativas y el entorno que rodea la adopción de alguna de ellas, sugiriendo posibles medidas a partir de las diferentes posturas sobre el tema, diferenciando la solidaridad y la capitalización individual, $y$ tomando en cuenta el entorno político de la reforma.

\section{El centro de poder}

En 1997 se promulgaría, después de un intenso debate con los actores sociales, la ley del sistema de seguridad social integral, difiriéndose su aplicación, por considerarla privatizadora el nuevo gobierno, hasta incluirla en una ley habilitante en 1999, sin resultado concreto. Poderes especiales se intentaron conceder de nuevo al Ejecutivo el año siguiente, sustituidos al final por una Comisión Presidencial en el marco de iniciativas de carácter económico.

En el primer papel de trabajo elaborado, de septiembre de 2000 , el sistema diseñado contenía un fuerte sesgo financiero al adscribir al Ministerio de las Finanzas Públicas, las oficinas propuestas de recaudación de las cotizaciones, de información y una superintendencia, limitando sobremanera la capacidad de una comisión rectora que fungiría como cabeza dirigente del sistema.

Se acercaba el ante proyecto en esta primera versión al terreno bancario, muy limitado para hacer realidad el principio de universalidad postulado por uno de los fundadores de la seguridad social moderna, William Beveridge (1942). Para él este principio significaba "un proyecto completo de seguros sociales que abarcara a todos los ciudadanos y no sólo a quienes trabajaran para patronos, asegurando a todo el mundo por lo que todo el mundo necesita: pensiones de vejez, gastos de entierro y cuidados médicos." $Y$ es que, la seguridad social no es una cuestión de rendimiento y de mera regulación; es una cuestión social cuyo gabinete debe estar instalado en otro sitio; primero, porque su aparato administrativo así lo exige y segundo, porque la parte financiera es apenas uno de los eslabones de una compleja cadena de pasos, donde; la retención de información, como el peligro de no darla, es un riesgo administrativo que no hemos podido entre nosotros extirpar. Véase por ejemplo, la ley de 
simplificación administrativa, (Gaceta Oficial No. 5.393 de 22 de octubre de 1999) que pretende abreviar los trámites de presentación de documentos por ante la administración pública, reduciendo las formalidades que entraban los procedimientos, pero inaplicada hasta ahora porque sus destinatarios no han procedido a las reformas del caso, da una idea de la magnitud del problema, sin necesidad de afiliar la seguridad social a una política de cabeza financiera. Por otra parte, al detallarse el flujograma de información (Unidad de Reforma, 1998) como los plazos de afiliación y contratación con las administradoras de fondos de pensiones (AFPs), los traslados de afiliados entre aquéllas, las solicitudes de constancias de retención de cotizaciones, situaciones varias de vejez prematura que requieren de procedimientos especiales, la atención y resolución de conflictos, los pagos de indemnización únicas, de beneficios y beneficiarios que causan prestación por sobrevivencia, invalidez, por enfermedad, etcétera; se observa la gran cantidad de situaciones, movimientos y demandas que exceden en mucho la capacidad del despacho de hacienda, que requeriria de más compartimientos organizacionales, porque apenas tiene el del mercado como objeto de estudio y acción de rutinas. La participación de las finanzas públicas es forzada por la crisis económica y orientada por los multilaterales, dado que los escuchas nacionales están en estos ministerios, aplicadores iniciales de los métodos de ajuste cuando la bonanza ya no cohabita como medio de distribución ordenado por las elites políticas. Existe además una explicación económica, y es que los sistemas de reparto, constituyen una deuda implícita para los Estados que deben corregir los desequilibrios fiscales aumentando la tasa, el gasto público o los impuestos. La escasez e insuficiencia de recursos, hace que las soluciones a los problemas de la seguridad social sean económicas y financieras. Mayores costos en salud, la elevación de los tiempos de vida, el desempleo y la evasión, han mermado recursos que no pueden ser sustituidos con aportes del Estado, muy debilitado por la expansión de la informalidad, o por ser su influencia menor que otrora.

No debemos pasar por alto tampoco que las necesidades sociales son muy diferentes a las del capital y como apunta Claramunt (1999), las reglas sustanciales del régimen capitalista no resultan en ningún caso alteradas por la seguridad social para pretender entonces una reforma de sus bases de conducción social por mecanismos exclusivamente financieros. Esta visión parcial del problema, tomando como paradigma la aplicación de recetas monetaristas en lugar de recomendaciones de política social, es modificada favorablemente en la versión definitiva de febrero de 2001, como parte de una agenda de consultas realizadas por la Comisión Presidencial. Se alcanza un mayor equilibrio al trasladar la superintendencia al mando de la comisión recto. ra y otorgarle al Ministerio del Trabajo, la conducción de la secretaría técnica de aquélla. No obstante, un sistema tan complejo como el de seguridad social, complejo por los subsistemas que lo integran y la participación privada supervisada, requiere de un ejecutivo permanente que parece no encontrarse en la comisión rectora integrada por los ministerios invo- 
lucrados, incluida la Vicepresidencia de la República, sin tener ninguno de ellos el tiempo suficiente para atender funciones previsionales tan exclusivas.

\section{La privatización}

Si entendemos a la privatización como el manejo de lo que antes era público por los privados, como ha sucedido con las empresas eléctricas y de telecomunicaciones, la aplicación conceptual usada, es similar en la seguridad social, antes pública, ahora parcialmente privatizada en uno de sus componentes, por eso es que preferimos decir privatización parcial. Esta precisión es útil para el manejo político del asunto, porque es la gestión, la operación de nivel básico la que se privatiza y no todo el sistema (La retórica política omite generalmente este asunto).

La primera experiencia fue de administración tripartita: Una mesa directiva en la que patrono y trabajador tenian representación. Teóricamente, la combinación capital / trabajo debia producir control de los recursos aportados, orientación concertada del programa de beneficios y ampliación de la infraestructura. Esto ültimo fue lo más positivo, porque en la práctica, el balance fue muy distinto.

La segunda experiencia y que corre en paralelo con el tripartismo, es el de la gestión propia o autogestionaria, que se hace acompañar de una subvención pública muy fuerte. Esta administración auto-tutelada de los fondos y servicios en numerosos entes públicos, gremios y fuerzas armadas, no se extiende a toda la población, por lo que el bienestar tiene estos dos derroteros clasistas bien diferenciados, uno, relativamente amplio, para un 30 a $40 \%$ de la población en América Latina; es el de los seguros sociales de administración tripartita, y el otro, para sectores menos numerosos aunque más representativos políticamente, debido entre otros factores, a la fuerza gremial, a la participación en procesos de consolidación democrática, a movilizaciones generales y lobby.

La tercera experiencia es la gestión mandatoria. En este caso, las AFPs se constituyen en mandatarias de los afiliados que pagan por sus servicios y el Estado revisa o termina con sus funciones regulativas, productivas y redistributivas, reemplazando su dirección politica institucional por mecanismos de mercado, al decir de Dombois y Pries (2000). En el presente documento se observa que están dadas las condiciones para que esto ocurra, de forma distinta a lo sostenido en el discurso político.

Una consideración importante que hay que hacer con respecto a la gestión mandataria, tiene que ver con la instalación de las AFPs, agenciadas por personal bancario y de capital público o privado: Oficinas activadas en un mercado laboral deteriorado, donde cada 7 de 10 puestos de trabajo creados, se van a la economía sumergida (EI Nacional de 0811-2000).

Es decir, las AFPs laboran en un mercado con restricciones y tensiones, porque ofrecen sus servicios a los que no tienen posibilidad de contratar y desean la permanencia de aquéllos que no tienen tal cualidad. Y claro, este tipo de empresa que recibe, administra y acumula fondos privados, privados porque son de los tra- 
bajadores afiliados, no tiene por que interferir con la distribución de los recursos a la sociedad, ni con el papel rector que le corresponderia al Estado. Pero el mercado que se monta arriba del otro-el de pensiones sobre el laboral- tiene sin embargo deficiencias y fallas. Veamos:

FALTA DE INCENTIVOS PARA PAGOS VOLUNTARIOS. Esta es una deficiencia que puede originarse cuando el mercado no es competitivo y la tasa de interés es negativa.

En el decreto-ley de pensiones de 1998 se había dispuesto que los afiliados podían realizar aportes voluntarios para aumentar la pensión o anticipar su retiro, pudiendo disponer al momento del mismo, del saldo acumulado correspondiente a los aportes voluntarios. Además disponía el artículo 17 que el afiliado igualmente podia realizar aportes voluntarios a una sub-cuenta especial, de los cuales dispondría libremente, pero sin gozar de la prerrogativa de la inembargabilidad. En el último proyecto conocido, se permiten como es de suponer, los ahorros voluntarios, pero no existe mención a la subcuenta propuesta por la comisión legisiativa de 1998 encargada de supervisar la habilitación conferida al expresidente Caldera. Tampoco en el proyecto confeccionado para la habilitación conferida al Presidente Chávez aparece este mecanismo adicional de ahorro. En cualquier caso, los aportes libres dependerán de la capacidad de ahorro y del nivel de confianza del ahorrista.

ESCASA INFORMACIÓN. Esta deficiencia alude al niesgo moral, donde el afiliado podría obtener provecho a expensas del sistema-Estado. En este caso, el asegurado influye en la pérdida de una pensión indefinida a un costo menor que la ganancia esperada sin que el Estado pueda saberlo (Solís Soberón y Villagómez, 1999²). Otra deficiencia relativa a la escasa información, se denomina selección adversa: El afiliado oculta información al oferente del seguro. La compañía se cubre con una prima más alta pero los asegurados sufren ahora los costos y la empresa contratante los riesgos malos. Cuando la cobertura se hace obligatoria para mujeres y hombres en edad avanza$\mathrm{da}$, las aseguradoras intentan esta vez ignorar su contratación.

MONOPOLIO. Las Administradoras de Fondos de Pensiones (AFPs) cobran en todos los países un precio mayor por comisión a su costo marginal, el que es menor a su costo medio. Esta falla, propia de un mercado concentrado, se produce cuando el costo de producción disminuye conforme aumenta el volumen, generándose un monopolio que impide la entrada a nuevos competidores. Puede que exista una legislación antimonopolio, pero pocos operadores hacen proclive un acuerdo de precio. En la legislación de 1998 se estableció un sistema de comisión con límite legal con las dificultades que ello pudiera generar (ausencia de incentivos, afectación del servicio, presiones buscando reformas legales, etcétera). Se estableció también, estructurar la comisión sobre la remuneración, lo que aseguraba conocer con exactitud el costo de la administración de la cuenta. Pero siendo el mismo para todos, suponía que el trabajador de mayor ingreso pagaría más. Este típico subsidio cruzado no beneficiaría en realidad a los trabajadores de bajos ingresos sino a las administradoras, aumentando su margen de 
utilidad que se incrementa adicionalmente con los acuerdos que hace con las aseguradoras a las que le ofrece el grupo de afiliados que la han contratado. Finalmente, en la legislación propuesta de 1999 , se propuso un sistema de comisiones sin límite legal y sobre el saldo de la cuenta, menos transparente para el trabajador.

El problema de las comisiones parece estructural al sistema de capitalización individual: No han bajado y consumen buena parte de la pensión futura. Lo que se recomendó desde el poder ejecutivo chileno (Superintendencia de Administradoras de Fondos y Pensiones, 1999) para incentivar la competencia, es permitirle a los afiliados negociar la comisión, individualmente o por grupos, a cambio de una permanencia prolongada en la empresa administradora de los fondos, lo que uno de los mentores principales del sistema, Piñera (1995), había rechazado desde el comienzo de operaciones del régimen en 1981, cuando una representación sindical, le ofreció afiliar colectivamente a los trabajadores, lo que consideró chocante a la libertad individual, esencia del sistema chileno.

RIESGOS DE MERCADO. Esta es una falla, implícita, mas que una deficiencia, y es cubierta con algunas medidas regulatorias para atemperar la incertidumbre financiera. Pero, los ciclos económicos no dependen exclusivamente de las decisiones internas; sino del comportamiento de la economía norteamericana, del euro, la baja tasa de ahorro y los déficit comerciales, por citar algunos ejemplos.

Entre las medidas reguladoras están la contratación obligatoria de la custodia de los instrumentos que pertenecen a los fondos; la obtención de un rendimiento real mínimo anual, garantizado con una reserva de contingencia que formará parte del fondo y que se expresa en el exceso de rentabilidad real, y adicionalmente, una cantidad aportada por la misma administradora, denominada encaje, invertida en el mismo fondo administrado. Si la rentabilidad real del fondo es menor a la mínima, será cubierta por la reserva de contingencia; si esta no es suficiente, se echará mano del encaje o reserva adicional; y si todavía no se cubre, la AFP deberá inyectar capital de los accionistas. De no obedecerse el mandato legal, la entidad será liquidada, siendo el último garante el Estado, si la legislación así lo contempla, como ocurre por ejemplo en Chile. De lo contrario, se utilizarán los recursos de la liquidación para cubrir la diferencia de rentabilidad.

Los críticos de los fondos de pensiones sostienen que el programa de seguridad social no puede ser reemplazado por una economia privada; que más allá de la retórica estatista/antiestatista, el sector público de seguridad social esta lleno de realizaciones positivas. El grueso de hospitales y ambulatorios es para Petras (1999) una muestra que evidencia el papel fundamental que pudiera tener el Estado.

Es menester hacer algunas precisiones: La primera de ellas es que el Estado no puede abandonar la política de bienestar. Ello no seria posible ni en el liberalismo más puro: $A$ finales del siglo $X I X, B i s m a r c k$ se planteó la intervención en áreas no reguladas, con un seguro de cobertura obligatoria para los trabajadores, desde arriba, por la presión marxista de los de abajo. En el Reino Unido, a co- 
mienzos del siglo $X X, 0$ en EEUU durante la gran depresión de 1935; el Estado debió asumir algunas responsabilidades, porque los intereses generales de la sociedad estaban en juego.

En segundo lugar, como es necesario redistribuir recursos para compensar el menor ahorro de ciertos trabajadores, de ciertas regiones y de grupos especiales, la privatización de la seguridad social, no puede ir más allá de operaciones desconcentradas. $O$ cuando los servicios, al decir de Solís Soberón Y Villagómez (1999b) son imperfectamente ofrecidos por mecanismos privados, justificando la participación del Estado.

Este despeje permite a su vez:

- Que el Estado concentre sus esfuerzos en los que menos tienen. Esto es una acción política.

- Que el ciudadano se haga co-responsable del ahorro general y de su pensión en particular, en la medida de sus posibilidades. Es claro que las posibilidades fiscales cuentan mucho pero las del afiliado lo son más en la medida que paga impuestos y devengue buenos salarios.

- Que el Estado permita que agentes privados se dediquen a la administración de los fondos de pensiones, por ser una actividad de servicio.

Cualquier pretensión para favorecer la existencia y posterior ampliación de un sistema provisional, parcial o totalmente privado, no carece de lógica, sin dejar de lado, consideraciones políticas que trataremos cuando lleguemos al punto de las posturas ideológicas.

La inversión de los recursos, por administradores especializados y lejos de la tentación del gobierno para financiar gasto corriente, pone en contacto a los afiliados con el derecho de propiedad sobre las contribuciones realizadas, junto con algunas garantías para su recuperación (Diaz, 1999a).

La privatización ha surgido como reacción a la mala gestión del Estado y por el abandono al que estaban y están sometidos los afiliados. Pero supone también, como lo hemos indicado supra el nacimiento de un negocio en un mercado como el de capitales donde el riesgo es lo normal (Martínez Vivot, 1998). Hasta ahora el sector privado interesado en la apertura no oculta nada. El negocio, dicen, es bancario, mientras el Estado debe hacer todos los esfuerzos para reducir el sector informal y el desempleo. Por otra parte, reconocen que los ingresos de las clases sociales $D$ y $E$ que aporten $8 \%$ de su salario durante 30 años, y colocados a un rendimiento de $5 \%$, obtendrían una pensión equivalente al $60 \%$ de su salario, nunca equivalente al salario mínimo exigido por la Constitución (Asociación de Fondos de Pensiones, 2000). Dicho de otra manera, sabrán a quien buscar.

No hay que olvidar además que buena parte de la seguridad social se encuentra ya privatizada por las grandes empresas que han creado sus propios sistemas previsionales o por la contratación de coberturas adicionales a la existentes en el sector público, junto con la gran cantidad de sisternas paralelos de administración privada con aportes del fisco (Díaz, 1999b).

El punto es, si la privatización es para mejorar la cobertura, ampliando la capacidad de maniobra del Estado o es 
un negocio ineficiente socialmente, es decir, un mal negocio.

\section{Objetivos y funciones del programa de seguridad social}

Sin duda que hay un objetivo básico, el de mantener la calidad de vida del ciudadano. En términos más concretos, no es otra cosa que mantener el poder de compra para atender necesidades, riesgos y contingencias.

Un objetivo aportado por los neomanxistas, es el de reponer la fuerza de trabajo para favorecer la acumulación, lo que en términos más convencionales signíficaria mantener una salud laboral adecuada.

La redistribución de recursos de modo inter-temporal, el compromiso que se asume con la generación anterior o la posibilidad de repartir los riesgos y distribuir los beneficios, son objetivos muy caros que suponen el funcionamiento de un sistema basado en la solidaridad.

La integración social, otro de los objetivos apuntado por Barr (1992), puede lograrse cuando los beneficios / indemnizaciones no tienen que ver con la posición económica, y el bienestar es concebido como un derecho; más que como una dádiva.

El último objetivo toca lo concerniente a la seguridad económica deseada durante la vejez, o por la pérdida del empleo, el nacimiento o la matemidad.

Existen aparte, objetivos más específicos, detectados de encuestas realizadas, por Clementina Acedo en 1987 y más recientemente, por DATANALISIS publicadas en EL UNIVERSAL en una edición de febrero de 2000 , son: El manejo eficiente de los recursos ahorrados e invertidos; el ajuste anual de las prestaciones dinerarias; el otorgamiento de una pensión mínima contributiva; la descentralización de los servicios de atención al afiliado y la administración eficiente de los fondos.

El fondo solidario por su parte, diseñado en el decreto-ley, suspendido sobre pensiones de 1998 (GO No. 36.575), apuntaba a lograr la sanidad financiera; la administración de los recursos por parte del sector privado, previa licitación; ofrecer información al público para el procesamiento de reclamos y consultas, aparte del procedimiento para el trámite de las cuentas individuales; la publicación de los estados financieros -como nunca antes se habia hecho-; pagar la pensión un mes después de hecha la solicitud; y una nueva arquitectura de gestión, como servicio autónomo sin personalidad jurídica, con menos personal que la nómina actual del IVSS y a cargo de un director ejecutivo con líneas de acción en el área jurídica, de informática, actuarial, de administración y recursos humanos (Reglamento que regula el fondo de solidaridad intergeneracional, GO No. 5301 Extraordinario del 29-01-99).La versión de la Comisión Presidencial le confiere al Ministerio de las Finanzas la administración del fondo, con las limitaciones ya comentadas en la primera parte del artículo.

Entre las funciones destacan: Reponer las pérdidas en el ingreso, es una de las funciones de la seguridad so- 
cial a través de la técnica del seguro, sucede asi con las prestaciones dinerarias de corto y largo plazo.

Puede complementarse el ingreso con una prestación dineraria cuando la capacidad de trabajo se ve disminuida por invalidez o desempleo parcial, también a través del seguro.

La pensión de vejez, es una prestación que sustituye el salario a través de un mecanismo de ahorro o a través de la técnica del seguro.

Existe una función primordial de provisión de servicios médicos, satisfechos directamente por los asegurados - a través de impuestos. $Y$ también, servicios total o parcialmente subsidiados, como las casas cunas, de descanso, vivienda, etcétera.

$Y$ finalmente, prestaciones no contributivas, conferidas por el Estado, prestaciones que corresponden mas propiamente a la asistencia social.

El despliegue estatal como se nota, es amplio, en materia de salud, infra-estructura y prestaciones no contributivas. Otra precisión importante es que el seguro abarca un radio de acción prestacional considerablemente mayor al mecanismo de ahorro, circunscrito al programa de pensiones, como nivel complementario u obligatorio. En este sentido, recomendamos combinarlo con un régimen de seguro contra la volatilidad financiera, como se expone más adelante.

\section{Objetivos por gerencia}

El programa de seguridad social debe ser un proyecto de sociedad, de nin- guna manera significa reflotar exclusivamente el ahorro interno a través de los fondos de pensiones, este es un objetivo de segundo plano. Es concebir mas bien a la seguridad social como sistema contributivo para toda la población, que tiene planos muy dinámicos, los que distribuidos por gerencia serian:

El de la gestión, que corresponde a una administradora de pensiones, al servicio de empleo, al ambulatorio, a la banca recaudadora, etcétera. Corresponde a esta gerencia operativa, la incorporación de los afiliados y su registro, incluyendo los especiales, los contratos de aseguramiento de los fondos, la supervisión de las condiciones laborales y la extensión de períodos de protección o indemnización.

A la gerencia financiera, corresponde conformar o presidir la junta de inversiones y tener (o no) adscrita la superintendencia de pensiones (o la de todo el sistema, como es la propuesta de la Comisión de Seguridad Social) Si esto último se plasma -la adscripción de la supervisión-, debe tenerse especial cuidado en tres puntos:

- El sistema de rendición de cuentas debe ser a la máxima autoridad, porque si no, ni se gobierna ni planifica.

- Tener especial cuidado en el modo cómo se designa el funcionario, quien presidirá la supervisión.

- Garantizar la necesaria independencia, con la que debe contar el organismo para no ser ahorcado por decisiones políticas, ni por el sector privado que absorba después con facilidad su personal entrenado.

A la gerencia de planificación se le asignan los estudios de opinión, los ac- 
tuariales y los del mercado laboral, la revisión de fórmulas de ajuste, monitoreo, la agenda presente y futura del sistema, la sala de situaciones, el asesoramiento yel diseño de políticas. Existen funciones que se proponen a la secretaría del consejo de seguridad social, adscribiéndolo al Min-Trabajo, sensiblemente debilitado en la discusión de la reforma, serían: Coordinar los proyectos de reglamento del sistema; preparar sus resoluciones y las campañas de divulgación; elaborar el plan anual de formación de recursos humanos; proponer registros especiales de afiliación; publicar los resultados de las investigaciones; ordenar informes y estudios especiales a los entes que conforman el sistema y convocar al Consejo de la Seguridad Social del modo que se acuerde.

La superintendencia por su parte. es la que tiene el día a día de los fondos, de las administradoras y del propio IVSS, después de la decisión política de dejarlo en pie. Alguien debe estar facultado para establecer funciones de coordinación y exigencia de información, sea un Ministerio o el Consejo que se propone en el proyecto de la comisión, dependiendo de quien sea el rector.

A este respecto no es recomendable el fraccionamiento del sistema entre el IVSS, Ministerios y Comisión, la autoridad debe quedar absolutamente clara. No es recomendable tampoco una reforma sin concederle a los actores sociales la posibilidad de participación en temas que le son cruciales. El dilema actual es que la dirección parece ir y venir del IVSS al Min-Hacienda. La fotografía en este caso, es bien pálida, porque es una pintura de evasión y desencanto general.
Uno de los objetivos de la gerencia de planificación, es el de uniformar los regímenes de jubilación, lo que implica aumentar la tasa de contribución de los existentes, no permitir nuevos regimenes $y$ capitalizar los actuales en cuentas individuales o fondos solidarios, dependiendo del régimen general que se adopte.

Otro de los objetivos, es el de incorporar a los independientes, sugiriendo un subsidio a la tasa de afiliación, sobre todo si se adopta un régimen mixto, obviamente más caro por sus dos componentes financieros.

El objetivo terminal no es otro sino el de la universalización del sistema, apuntando a la distribución de los recursos que la sociedad produce, construyendo uno donde este objetivo ciudadano y universal sea posible. La fórmula redistributiva significa que los ingresos más altos contribuyen al financiamiento de las prestaciones de los que devengan los salarios más bajos. El estado social aporta subvenciones directas a trabajadores de segmentos especiales para facilitar su incorporación al sistema (trabajadores independientes y rurales). Se reduce adicionalmente la presión a la nómina, eliminando aportes que no van en beneficio real de los trabajadores y se aumentan los salarios para hacer frente al reajuste, en alza, de la tasa de contribución. Se garantiza por último, una pensión mínima, cumplida la edad y número de contribuciones necesarias para financiarla.

\section{El recurso humano}

La seguridad social requiere de profesionales que elaboren su boletin diario. No hay que olvidar ni por un instan- 
te que ella en la época de la post-guerra fue una comunidad sin intereses prefijados, un manto del estado de providencia que debía devolver la civilidad perdida en la II guerra, comprometiéndose los ganadores a conseguir mejores niveles de trabajo y prosperidad. Pero al intervenir los privados, la comunidad es ahora de intereses: Con el IVSS son políticos, con las AFPs son financieros, con ambos; es decir, con un sistema mixto, la tarea obviamente es mucho más compleja. En esas condiciones hay que monitorear al sistema para evitar zonas de desastre. Esto se hace desde la gerencia social, llámese ministerio, unidad, dirección, la superintendencia del sistema y el servicio de información; no desde comités que nunca o rara vez se reunirán, como sería el caso de la Comisión Rectora propuesta.

Uno de los problemas que enfrenta la reforma, es no contar con una opinión formada y formante, con un liderazgo de opinión que se nutra del propio sistema. El país no ha construido su concepto. Las pautas constitucionales son poco claras y dispersas. Culturalmente tampoco existe un modelo que no sea el del IVSS, con cada vez menos trabajadores con que operar: 5 millones de trabajadores informales y un $13 \%$ de desempleo.

Esta conciencia previsional y de opinión se forma con profesionales egresados de nuestras universidades; con funcionarios preparados y laborando con unos objetivos que deben afinarse en el proyecto de reforma. Esos objetivos hay que discutirlos abiertamente, unos forman parte de una experiencia que no poseemos, como si la tienen los uruguayos, chilenos y argentinos, con poblaciones más envejecidas, pero también con par- lamentos y escuelas creadoras de doctrina que han explicitado por y con más tiempo sus sistemas reformados desde la década de los ochenta.

La claridad de los objetivos permite formar el personal necesario, además de entrenar, convenir con casas de estudio y abrir licitaciones nacionales e internacionales de apoyo al servicio.

En los reglamentos promulgados de 1999 aparece por vez primera la intención de formar el recurso humano: Se les otorgaba el carácter de funcionario público a los que laborasen en el fondo solidario, organizado como servicio autónomo, aparte de una gerencia interna encargada de su desarrollo (artículo 24 y numeral 11 del 29 del reglamento que regula el fondo de solidaridad intergeneracional).

El reglamento sobre la adecuación patrimonial y encaje de las AFPs, obligaba a éstas a contar con un sistema de gerencia de riesgos y el suficiente personal adiestrado en el uso y manejo de modelos sofisticados en el área de negocios, control de riesgo, auditoria y soporte (artículo 5).

Los que aspirasen actuar como intermediarios del subsistema de pensiones, debian presentar un examen de suficiencia profesional ante un jurado designado por la superintendencia (artículo 6 del reglamento que regula el derecho a la información de los afiliados ante las AFPs).

$Y$ en el reglamento orgánico de la superintendencia del subsistema de pensiones, una cámara de recursos humanos, tendría tres departamentos, uno de reclutamiento y selección de personal; otro de inducción y capacitación y un ter- 
cero de evaluación y nómina (artículos 22 al 25). Y en particular, para el área de las AFPs, aplicaria la superintendencia el examen a productores 0 intermediarios, otorgando un número de registro válido por dos años, renovable cuando se acreditase un mínimo de 40 horas de capacitación (numeral 12 del artículo 32).

\section{El régimen financiero}

Pueden ofrecerse tres opciones de instalación de un sistema financiero de seguridad social: De capitalización individual, con un impuesto a la nómina, de uno a tres puntos adicionales, para complementar un fondo solidario sostenido por el Estado. Este esquema de subsidio garantiza las pensiones minimas en la franja solidaria, homologadas al salario mínimo, causando un crash fiscal, por el déficit calculado por no menos de dos generaciones, unos 40 años, de acuerdo a cálculos de la OIT (1998).

De aprobarse un régimen de capitalización individual, debe tenerse en cuenta antes que:

- La deuda previsional puede financiarse de diferentes maneras, que no es una deuda impagable como normalmente dicen los adversarios a los sistemas solidarios, sea retrasando la edad para pensionarse, sea bajando la pensión, o aumentando las tasas o los impuestos; la deuda se financia. Aparte, se requiere de una mejora en el comportamiento del empleo, la mejora de la recaudación y la afiliación. Lo que debe quedar claro entonces, es que la adopción del régimen no puede ser asumida en términos de propaganda o de oposición pura y simple a sistemas solidarios, mayoritarios, en comparación con la capitalización individual obligatoria.

- La sustentabilidad de un régimen mixto (individual y solidario), dependerá de no crear nuevos desequilibrios, por lo que no es admisible un régimen que nace fuertemente subsidiado.

- Las obligaciones auto-financiadas no pueden obviar el riesgo moral, ya explicado.

La solidaridad por su parte, garantiza un beneficio definido que puede ser igual o superior al salario mínimo.

La solidaridad para funcionar requiere de legitimación política y el IVSS no la tiene, aparte, necesita de una redistribución de recursos que con las tasas actuales de cotización y riesgos no se alcanza.

La tercera variante, es la de un régimen solidario mixto autofinanciado, de reparto o capitalización colectiva parcial, que provea una pensión básica. Los trabajadores aportan a ambos regímenes, de $\mathrm{Cl}$ y solidaridad. Los de mayores ingresos aportarian una cantidad adicional al fondo solidario, como se aprobó en la reforma de 1998. Llegado el momento para pensionarse y no existiendo recursos suficientes para comprar la pensión, el sistema solidario provee la prestación dineraria, sobre la base de los salarios de toda la carrera laboral, convenientemente indexados a la inflación, lo que quedó pendiente en 1998, salvo una redacción que se repite en el anteproyecto del 2001 en la que el Superintendente determinaría el modo cómo las pensiones debian preservar su capacidad adquisitiva. 
Esta variante ni las anteriores, excluye la libertad de contratar individual o colectivamente, previsiones complementarias por encima de los beneficios definidos en la solidaridad y de la cotización definida, en la capitalización individual, y hacia abajo, pensiones asistenciales ofrecidas por las regiones, previo examen de recursos.

Queda claro que el sistema de cotización definida es más caro al no existir solidaridad y es menos predecible. Una combinación de sistemas es probable entonces, pues evita la oscilación del precio de la jubilación y permite registrar los aportes individualmente. ¿ Pero cuál es el entorno que rodea al sistema mixto?

La tentación para hacer la reforma con petróleo es fuerte cuando PDVSA aporta mensualmente por concepto de impuesto sobre la renta, 435 millardos de bollvares. Sin embargo, los recursos petroleros son lo menos en el ramo de los ingresos previstos para el presupuesto del 2001 , según estimaciones del Ministerio de Finanzas, y aparte de eso, la deuda pública aumentará en el 2001 en más de 3 millardos de dólares (El Nacional, 09-11-2000).

En rigor, las variables macro en su mayoria se aprecian favorables: Las reservas internacionales, sobre los $18 \mathrm{mi}-$ llardos de dólares; la tasa de interés activa promedio ha disminuido -aunque sigue siendo alta-; la inflación ha descendido, pero la actividad económica sigue paralizada y por lo mismo, la intermediación financiera es escasa. El salario mínimo no se acerca al costo de la canasta básica -Bs. 631.571 -, lo que explica la caída del consumo interno, de 10 millones de personas con ingresos iguales o inferiores al mínimo (EI Nacional de 06 y 09-11-2000).
La morosidad con el IVSS es alta para cualquier organismo recaudador que pierde oportunidad para la inversión y no tiene un adecuado flujo de recursos. Empero, la facturación no es fiable, porque no existe la actualización requerida, por empresas que se trasladan, cierran o reducen personal. La supervisión de las cobranzas es clientelar, inefectiva y reactiva. Existe un problema estructural expresado en bajos niveles de información de entrada y oportuna salida de los estados de cuenta. Han sido frecuentes los operativos, los llamados públicos y la limpieza de deudas por "convencimiento" y no con las probanzas del caso. El reducido espacio de la autoliquidación, impropio para las pequeñas y medianas empresas, y la inexistencia de medidas activas para estimular el pago de los compromisos parafiscales, frena la recuperación de las cotizaciones. Tampoco existen políticas activas de mejoramiento de la recaudación, como por ejemplo, la exigencia de la solvencia para tener acceso a créditos y la aplicación de sanciones tributarias. Sin embargo, mi tesis es que ninguna de estas medidas, torcerá el desplazamiento a la economía informal, donde ninguna cobranza puede ser ejercida o los aportes estén por debajo de los topes establecidos.

El juego es defensivo para el trabajador y cualquier medida activa, como sugerir medidas policiales, no podrá resultar. Al revés, el juego claramente ofensivo para el IVSS no esta dando resultado para la economía que debe soportar un mayor financiamiento de las pensiones y jubilaciones en curso, con cada vez un menor número de aportes. Además, el peso de los impuestos y la necesidad de 
crear otras fuentes de financiamiento interno para equilibrar el gasto, sugiere que la población opte por cancelar aquellos impuestos que provoquen resultados tangibles. La homologación, al no tomar en cuenta los años de esfuerzo activo, confisca los salarios del trabajador, capturando baja recaudación. Si los trabajadores aprecian que el esfuerzo del ahorro para todos es el mismo, no podrá permanecer en pie ninguna campaña (riesgo moral). La evasión puede practicarse más rápido que la coacción. Si en cambio; las cotizaciones tienen un vínculo con las prestaciones, donde el ahorro tiene un mérito, las respuestas son más satisfactorias.

La reforma, y esto es quizá lo más importante, debe considerar a la hora del diseño financiero, los costos laborales: El previsional, no debe ser superior al $25 \%$ de la nómina, porcentaje resultante al comparar la tabla de cotizaciones vigente en el banco de información de la OISS, en la medida que se recuperan los salarios reales, como resultado de la desaceleración de la inflación. Las cotizaciones más altas se pagan en Argentina, Brasil y Uruguay, en ese orden. La propuesta presentada en la habilitación legislativa de 1999, nos ponfa por encima del $50 \%$, incluyendo el INCE, la Cesta Ticket, prestaciones dinerarias y médicas, es decir, todo el paquete previsional. La de la Comisión Presidencial tiene un costo indirecto de nómina de 30,55 a $39,55 \%$ sin incluir la cesta ticket (que se ajusta por unidades tributarias, Bs. 13.200 en abril de 2001) y el INCE, el aumento es mayor con seguridad.

La rebaja de los costos laborales no salariales es una manera de alinear los costos nacionales con el comporta- miento de la productividad en el marco de la apertura comercial y financiera (Martinez, 1999). La propuesta que hacemos es la de eliminar algunas asignaciones para ajustar otras; si no, habrá que recurrir a formas legales, facilitando el despido, socialmente indeseable, o ampliando el abanico de contrataciones atípicas, lo que obliga a reforzar las medidas de supervisión y protección, las que deberán ser fiscalmente financiadas, creando así un círculo vicioso.

Es posible con esa disminución manejar las cotizaciones sociales al sistema sin crear problemas de desempleo o trabajo en "negro", sin recurrir a excesivos impuestos generales como fuente de financiación del gasto social, los que en definitiva no se descartan para evitar un aumento del coste laboral total que depende fundamentalmente, a la luz de comparaciones internacionales, del nivel de productividad del trabajo, y no de la magnitud de las cotizaciones sociales (EI País, 20-10-2000).

En nuestro caso, lo que está planteado es una disminución de las cotizaciones sociales, aumentando en paralelo la calidad del gasto social. Se ajustan en pensiones sin afectar a las generaciones futuras y el sistema de salud se financia con impuestos generales, sin afectar a su vez el nivel de empleo, eliminando la tasa de $6,25 \%$ vigente destinada a aquél. $Y$ en lo que respecta a la actual generación, ésta ya ha sufrido la quiebra de su sistema de seguridad social y no tiene por que enfrentar aumentos que sólo alcanzarán a una pensión mínima para incorporarlos al nuevo sistema de manera obligatoria como lo propone la Comisión Presidencial en el anteproyecto de pensiones. 


\section{Posturas ideológicas}

Existen unos preceptos de cardenal cortantes, considerables, excesivos, que liquidan por revancha lo que se hizo bien después del acuerdo tripartito de 1997 o impiden ver con agudeza lo que puede corregirse sin mayor esfuerzo. El desdén por lo hecho es tan perjudicial como el de no reconocer que lo anterior es revisable.

Lo que se pretende introducir, antes y ahora, es un régimen de capitalización individual, que tiene dos significados: Es una ecuación que revela un secreto universal, el egoísmo de las decisiones que financian mi futuro y no necesariamente el de la sociedad, representa la decisión de un afiliado que no quiere más dependencia del Estado que se libera a su vez de ejecutar pagos financiados con ingresos corrientes o extraordinarios, 10grado sea el autofinanciamiento, definido de antemano en la cotización.

La capitalización individual, segundo significado, expulsa en principio a la solidaridad y como principio, a los compromisos del Estado de providencia, y a la izquierda que rechaza por militancia el individualismo. Los efectos de esta operación con fines de lucro para quienes 10 administren, a contrapelo de lo dispuesto en la Constitución (artículo 86) puede resumirse de esta manera: Los fondos de pensiones pueden aumentar el ahorro $y$ la producción nacional, supuesto que dependerá del precio del crédito, la remuneración de la inversión y la deuda previsional que financia el Estado con los propios fondos, mientras más alta, y sin ser explícita; los compromisos fiscales son mayo- res a los estimados, dependiendo del reconocimiento de las cotizaciones abonadas, del cómo se maneje la transición y el porcentaje de recurrencia a pensiones minimas satisfechas fiscalmente, cuando el afiliado las demanda por razones distintas a sus bajos ingresos (riesgo moral).

Pero la introducción de un régimen financiero no puede obviar un periodo necesario de transición, particular para cada país, tomando en cuenta lo siguientes aspectos: Los derechos adquiridos de los pensionados; si el programa se cierra, deberán atenderse con recursos fiscales y los derechos en curso, para lo que existen por los menos, cinco opciones posibles:

- Una es que se les reconozcan a los afiliados los aportes pensionales anteriores, lo que puede ser calculado de diversas maneras, con alguna fórmula de ajuste y el programa anterior se cierra.

- La segunda es que el afiliado escoja entre el nuevo programa y el que termina, lo que fuere más favorable.

- La tercera opción es crear un fondo especial con aportes de los afiliados que permanecerán en él con subsidios progresivos del Estado. La decisión es legal y no voluntaria.

- La cuarta, es conservar plenamente el programa anterior, sin aumentar la edad ni las contribuciones para los que decidan permanecer en él; pasado el periodo de selección, el programa antiguo no admite nuevos afiliados y en el futuro será auxiliado por el fisco.

- La última opción, es la de hacer un corte por edades para hacer una transferencia obligada al nuevo sistema. 
- Cualquiera de las opciones necesita el auxilio del fisco y exige al menos una batería de garantías para los afiliados. Estos puntos comunes requieren ser conciliados y no siempre es fácil la tarea, porque mientras más reconocimiento, mayor será la demanda fiscal, y a menor responsabilidad de la sociedad, menor será el reconocimiento de la deuda previsional. En esta oportunidad, la del Estado dependerá de la evolución del salario real y la tasa de interés, la tasa de crecimiento de la economía y variables demográficas.

En el ante-proyecto que reforma la ley marco de seguridad social, no existe mención al tema de la transición, difiriendo la discusión para cada uno de los subsistemas sin más remedio, debido a la falta de acuerdo. $Y$ en el proyecto de decreto ley, diseñado durante la primera habilitación al presidente Chávez en 1999, se preveía un corte de edades solamente para las mujeres de 45 o más años que quedarían exceptuadas del requisito de la edad de 60 años para pensionarse, pero pasarian de cualquier forma al nuevo sistema. Esto es omitido en el nuevo anteproyecto de pensiones de 2001.

La OIT propuso, durante la consulta tripartita de 1998, un mecanismo para los afiliados próximos a pensionarse de permanecer en el régimen anterior, reduciendo la carga fiscal durante los primeros años, haciendo un corte por edades: Las personas de 45 y 50 y más años (mujeres y hombres, respectivamente) integrarian un grupo cerrado que permanecería bajo las condiciones del sistema anterior, con una tasa especial de aporte.
Un último aspecto de la transición toca los aspectos institucionales, el cierre de organismos y la puesta en marcha de otros tantos, como los impositivos y los de supervisión.

\section{Efectos de los fondos de pensiones}

El ahorro nacional es uno de los efectos que se estiman positivos cuando se instala un programa previsional. La reforma hace explicita la deuda previsional $y$ los fondos pueden financiarla. Pero el gobierno se endeuda haciendo uso de ese ahorro, reduciéndolo en consecuencia. Aqui el electo se diluye. La reducción del gasto público es la alternativa que pudiera permitir el ahorro o el aumento de los impuestos para el logro del financiamiento. Pero las dos últimas soluciones afectarán a la generación presente (Solis Soberón y Villagómez,1999b). Pueden tomarse algunas medidas para incentivar el ahorro, por ejemplo, subsidiándolo; de esta forma, los intereses y las contribuciones, estarian exentos del impuesto sobre la renta. Otros ejemplos son, reducir el gasto público, implementar algunas restricciones de liquidez, fomentar incentivos al ahorro voiuntario, desarrollar el mercado de capitales, procurar un rendimiento de los fondos por encima de la inflación y aumentar el ingreso disponible, entre otros.

Pero la existencia de los fondos no determina el aumento del ahorro interno, supuesto no demostrado o controvertido al menos, por lo que dicen algunos estudios y reportes (CEPAL-PNUD, Iglesias, 
Superintendencia de Administradoras de Fondos de Pensiones de Chile). Lo que pueden hacerse son simulaciones, tomando en cuenta, siguiendo a SOLís Soberon y Villagómez (1999b) el crecimiento del PIB, la tasa de Interés real, el crecimiento del salario real, el crecimiento del número de afiliados, la densidad de las cotizaciones, la tasa de aporte, el modo de financiamiento fiscal, via impuesto o deuda, las comisiones cobradas, las aportaciones voluntarias, la disminución de otros ahorros $y$ las afifiaciones libres.

Otro efecto colateral de los fondos de pensiones, es el que concierne al mercado financiero, la importancia que adquiere, dado que se crean instrumentos de largo plazo para la inversión e indexados para así proteger el ingreso futuro de los trabajadores. Alheimer (2000) sostiene además que debería remunerarse adicionalmente su uso. Los instrumentos más seguros son los emitidos y garantizados por la República o el Banco Central, y los de renta fija, porque su valor no se disipa en el mercado. Los que pudieran tener una rédito mayor, son los de renta variable de sociedades anónimas o extranjeras pero con mayor riesgo. Los porcentajes de inversión y los tipos de instrumentos dependen de una comisión oficial de inversión, pudiendo la ley fijar los máximos de inversión con suficiente flexibilidad, to que es más seguro, en nuestra opinión, que una discrecionalidad demasiado amplia como la sugiere el anteproyecto de pensiones de la comisión presidencial del 2001.

Se desarrollan finalmente, emisores no bancarios e intermediarios financieros, aparte de un mercado de rentas vitalicias y cobertura de riesgos del trabajo.

\section{Conclusiones}

En rigor, la existencia de los fondos de pensiones no es puntal de crecimiento, si no hay donde hacer las colocaciones, deteriorando la rentabilidad de las cuentas individuales, las que deberán ser entonces protegidas en el exterior, beneficiando a un europeo $o$ a un norteamericano pero no a los trabajadores venezolanos.

Los aportes tienen que ser suficientes y regulares para garantizar una buena pensión, supuesto que dependerá de la estabilidad del empleo y de buenos salarios.

La solidaridad por su lado, es una categoría sociológica y financiera, propia de los seguros sociales, a la vez que política y religiosa. Redistribuye los recursos y el tiempo de cotización, y es por lo mismo, menos costosa. Sin embargo, se han distorsionado sus objetivos y expoliado sus recursos. En buena medida, los recursos de los propios asegurados fueron utilizados para el financiamiento del gobierno o mal administrados. Su indice de contiabilidad cada vez es menor y su manejo por el IVSS en las mismas condiciones de antes, con algunas maneras nuevas (sólo formas) no rehacen una solidaridad que muchos sectores demandan, aunque sin poner a riesgo su propio pedazo de la torta.

La solidaridad es necesaria pero ha sido regresiva; la cuenta individual por su parte, es una alternativa de cambio que capitaliza totalmente los aportes, pero para los buenos ingresos que la mayoría no tiene. 
El problema es que no hay régimen ni sistema perfecto, las diferencias reales entre la capitalización individual y la solidaridad como podrán apreciarse en el cuadro resumen siguiente, no son conciliables, pues incluso los regímenes mixtos, lo que hacen es recoger ambos lados de las costuras.

El discurso político sugiere las tendencias. Los hechos por su parte, ofrecen datos que determinan el proceso final de reforma: El proceso constituyente entre 1999-2000, ha justificado la reducción de grupos de interés, por varias razones, porque se expulsan, como algunas ONGs; se derrotan, como los partidos del establecimiento anterior, o se desplazan, como los sindicatos. El propio proceso de organización social es controlado para favorecer los cambios. Asi se hace con los poderes públicos, como la Fiscalía, la Contraloría, etc. A esto se agrega que para frenar la disidencia y contramarchas, las decisiones políticas deben centralizarse, sin ofrecer un marco para regular el consenso. A consecuencia de lo anterior, el bienestar social se diferencia de lo económico y los intereses sectoriales cuentan con un marco legal para su desarrollo, como en el caso de las telecomunicaciones, electricidad, petróleo y pensiones. El poder militarcivil interioriza sus vínculos con la clase capitalista y el sindicalismo es expuesto a una relegitimación que lo empuja a conectarse con la estructura estatal mientras la acumulación de capital se ve maximizada y la clase trabaja-

\section{Sistemas Previsionales Diferencias}

\begin{tabular}{|l|l|}
\hline \multicolumn{1}{|c|}{ Capitalizacion Individual } & \multicolumn{1}{|c|}{ Solidaridad } \\
\hline $\begin{array}{l}\text { Contrato individual explicito de administración } \\
\text { (análogo a un mandato) con una administradora, } \\
\text { cuyo costo está determinado de anternano, ope- } \\
\text { rando como un impuesto a la nómina. }\end{array}$ & $\begin{array}{l}\text { Contrato social implicito, sobre la base del deber } \\
\text { solidario que opera también como impuesto a la } \\
\text { nómina o generales, pero transfiriendo recursos } \\
\text { entre generaciones. }\end{array}$ \\
\hline $\begin{array}{l}\text { Riesgo Individual de inversión y sobrevida. El } \\
\text { monto de la pensión depende del saldo de la } \\
\text { cuenta y el costo de aquélla. }\end{array}$ & $\begin{array}{l}\text { Solidaridad Intergeneracional con justicia redis- } \\
\text { tributiva: Los que más tienen contribuyen con los } \\
\text { que menos tienen, transfiniendo recursos entre } \\
\text { sectores de ingresos. }\end{array}$ \\
\hline $\begin{array}{l}\text { Cotización Definida. El aporte se mantiene cons- } \\
\text { tante para una pensión financiada con los apor- } \\
\text { tes y el rendimiento. }\end{array}$ & $\begin{array}{l}\text { Beneficio Definido. El aporte es variable para } \\
\text { una pensión máxima }\end{array}$ \\
\hline Costo definido de inmediato. & Costo Programado y Progresivo \\
\hline Aportes, propiedad individual del afiliado. & Aportes, propiedad colectiva de los atiliados. \\
\hline Posibilidad de rescatar lo aportado & Imposibilidad de rescate. \\
\hline Capitaliza siempre. & Reservas Técnicas o Capitalización. \\
\hline
\end{tabular}

Elaboración propia. 
dora organizada se integra a nuevos mecanismos de control social y político. La pregunta que deberá hacerse en breve será quién se apropia del excedente social y los futuros endeudamientos a quiénes beneficiarán.

El Estado capitalista es por naturaleza receptor de las demandas sociales, independientemente del control ejercido, por lo que los problemas de centralización, burocratización y fiscalización son frecuentes, según Bowles y Gintis (1982). Las necesidades pueden ser aplazadas, disminuidas o desatendidas al largo plazo, lo que no ocurre todavía en nuestro caso, porque el gobierno expande el gasto con el propósito de legitimar el régimen, mientras avanza el proceso post-constituyente, teniendo recursos suficientes para ello, pero no tardando el resurgimiento de conflictos cuando sea necesaria la acumulación y el financiamiento del gasto (Olivas, 1991).

Lo dicho sugiere la existencia de un

Estado que tendrá escasa capacidad para intervenir, para actuar, porque pretenderá coparlo todo, liberando el mercado de pensiones como una ley sectorial con fuerte sesgo financiero, con provisión de pensiones mínimas financiadas con impuestos, por el alto nivel de endeudamiento y la asistencia a sectores no afiliados, siendo posible prever un estado de seguro social y con poca seguridad social.

\section{Comentario Final}

La reforma requiere de decisiones de Estado, fundamentadas principalmente en la universalización del sistema a tra- vés de la distribución de los recursos recaudados.

Como es una reforma social la que hay que hacer, el programa y sus objetivos no deben formar parte de una brigada financiera. De lo contrario, la agenda parlamentaria tendrá dos leyes de funcionamiento, una, la de la carrera privada e individual para procurar una pensión, de circuito cerrado y otra; la del IVSS, defendido gremialmente. Demasiados prejuicios deberán ponerse de lado, porque el sectarismo ha levantado fachadas verbales y no toca fondo, esperando que la seguridad social sea gobernable y amplia, al ritmo del discurso.

\section{Bibliografía citada}

Acedo, Clementina (1987). "Necesidades Juridicas y acceso a la justicia de un nuevo sector: Beneficiarios del Seguro Social". En Justicla y Pobreza en Venezuela. (Coordinador Rogelio Pérez Perdomo). Caracas.

Agencia Española de Cooperación Internacional, Organización Iberoamericana de Seguridad Social, Comunidad Europea. (1998) "Banco de Información de los Sistemas de Seguridad Social l beroamericanos". Edición Secretaria General de la OISS. Madrid-España.

Allheimer, Harald (2000). "Ley Laboral y Seguridad Social". Papel de trabajo (mimeografiado).

Barr, N. (1992). "Economic Theory and the Welfare state: A survey and interpretation. Journal of Economic Literature, Vol. $X \times X$.

Beveridge, William (1942). "Las Bases de la Seguridad Social" (Trad. Teodoro Ortiz). Fondo de Cultura Económica, serie Biblioteca de la Salud. 
Bowles, S. y Gintis, H. (1982). "The Crisis of liberal democratic capitalism: The case of the United States", Politics and society.

CEPAL-PNUD (1991). "Sistema de Pensiones en América Latina-Chile: Experiencia con el Régimen de Capitalización 1981-1991" (Iglesias, A. y Acuña, R.) Santiago, Chile.

Claramunt, Carlos (1999). "El Estado del Bienestar, objetivos, modelos y teoría explicativas". Ariel: Barcelona, España.

Díaz, Luis Eduardo (1999a). "Una lectura del Decreto-Ley del Subsistema de Pensiones" (mimeografiado).

Diaz, Luis Eduardo (1999b). "Realidad y Dogmas de los Fondos de Jubilación" en Reflexiones y Propuestas en torno a la nueva Constitución. Caracas. ILDIS. Fondo Editorial Nacional (José Agustín Catalá, editor).

Dombois, Rainer y Pries, Ludger (2000). "Relaciones Laborales entre Mercado y Estado". Ediciones Nueva Sociedad. Caracas.

Iglesias, Augusto (1991). "10 años de historia del Sistema de AFP". AFP Habitat, Santiago, Chile.

Martinez Vivot, Julio (1998). "La privatización de la Seguridad Social" en Las Reformas de la Seguridad Social en Iberoamérica. Organización lberoamericana de la Seguridad Social (OISS). Madrid-España.

Martínez, Daniel (1999). "Costos Laborales". III Congreso Regional de las Américas. Las Relaciones de Trabajo en el Siglo XXI. Lima, Perú.

Olivas, E. (1991). "Problemas de Legitimación en el Estado Social". Trotta, Madrid.

Organización Iberoamericana de Seguridad Social (1998). "Las Reformas de la Seguridad Social en Iberoamérica". Edición Secretaría General de la OISS. Madrid-España.

Organización Intemacional del Trabajo. Oficina de Area y Equipo Técnico Multidiscipli- nario para los Países Andino (1998). "La Reforma de Pensiones en Venezuela: Costo de Transición. Analisis y Recomendaciones". En Revista Gaceta Laboral. Ediciones Astro-Data. Vol. 4 No. 2. Maracaibo-Venezuela.

Petras, James (1999). "América Latina: De la Globalización a la Revolución". Homo Sapiens Ediciones.

Piñera, José (1995). "El Cascabel al gato. La batalla por la Reforma Previsional". 6ta. Edición. Editorial Universitaria. Santiago de Chile.

Unidad Coordinadora del Programa de Seguridad Social (1998). "Flujograma de Información del Subsistema de Pensiones". Ministerio del Trabajo.

Solís Soberon, Femando y Villagómez, $F$. (1999a). "Las Pensiones" en La Seguridad Social en México. Centro de Investigación y Docencia Económica, CIDE. Fondo de Cultura Económica, México.

Solís Soberon, Fernando y Villagómez, $F$. (1999b). "La Economía de la Seguridad Social" en La Seguridad Social en México. Centro de Investigación y Docencia Económica, CIDE. Fondo de Cultura Económica, México.

Superintendencia de Administradoras de Fondos de Pensiones. Boletín Estadístico. Series 1997-1999. Santiago, Chile.

\section{Prensa}

El Nacional. "Se inicia reforma del régimen de seguridad social. Bajos salarios impiden que los más pobres tengan una jubilación decente" (Vladimir Hemández Lavado). Cuerpo E/2. Caracas 17 de Agosto de 2000.

El Nacional. "El desempleo sigue en pie. Vene. zolanos enfrentan caida de $\$ 140$ mensuales en el salario minimo" (Ana Diaz). Cuerpo E/2. Caracas 6 de Noviembre del 2000.

El Nacional "El desempleo cayó 13\% en septiembre" (Werther Sandoval). Cuerpo E. Caracas, 8 de noviembre del 2000. 
El Nacional "Continua la incertidumbre. La reactivación económica sigue esperando" (Omaira Sayago). Cuerpo E/2. Caracas 9 de noviembre del 2000.

El Nacional "El Ejecutivo abandona la estrategia de reducir sus pasivos en el exterior. La deuda pública avanza hacia el récord de \$33,8 millardos" (Andrés Rojas Jiménez). Cuerpo E. Caracas 9 de noviembre de 2000.

El Nacional "En lo que resta del año ingresarán Bs. 870 millardos. El fisco engorda con aportes cada vez mayores de PDVSA" (Alfredo Carcez Saavedra). Cuerpo E. Caracas 9 de noviembre de 2000 .

El Universal. Edición de febrero del 2000.

El País. ¿Deben reducirse las cotizaciones sociales? (José Antonio Herce y Juan Francisco Jimeno). España 20 de OCtubre de 2000.

El País. "Crece el rechazo a las privatizaciones" (Manuel Délano). España 11 de Diciembre de 2000.

EI País. "Blair propone ampliar la baja por maternidad hasta un año" (Isabel Ferrer). España, Diciembre de 2000.

\section{Anteproyectos de ley y leyes.}

Asamblea Nacional Constituyente. Proyecto de Constitución de la República Bolivariana de Venezuela. Caracas; diclembre de 1999.

Comisión Presidencial (1999). Proyecto de Decreto-Ley del Subsistema de Pensiones. Caracas.

Comisión Presidencial (2000). Anteproyecto de Ley Orgánica del Sistema de Seguridad Social. Caracas.

Comisión Presidencial (2000). Anteproyecto de Ley que regula el Subsistema de Pensiones. Caracas.

Comisión Presidencial (2001). Anteproyecto de Ley Orgánica del Sistema de Seguridad Social. Caracas.
Comisión Presidencial (2001). Anteproyecto de Ley del Subsistema de Pensiones. Caracas.

Congreso de la República de Venezuela. Gaceta Oficial No. 36.575. Decreto con Rango y Fuerza de Ley No. 2.993 que regula el Subsistema de Pensiones. 5 de noviembre de 1998.

Congreso de la República de Venezuela. Gaceta Oficial No. 5.393 Decreto con rango y Fuerza de Ley sobre Simplifcación de Trámites Administrativos. 22 de Octubre de 1999.

República de Venezuela. Gaceta Oficial No. 36.628. Decreto No. 3.237, mediante el cual se dicta el Reglamento Orgánico de la Superintendencia del Subsistema de Pensiones. 25 de enero de 1999.

República de Venezuela. Gaceta Oficial Extraordinario No. 5.301. Decreto No. 3.261 mediante el cual se dicta el Reglamento Parcial del decreto Ley de subsistema de pensiones que regula el Fondo de solidaridad Intergeneracional. 29 de Enero de 1999.

República de Venezuela. Gaceta Oficial Extraordinario No. 5.301. Decreto No. 3262 mediante el cual se dicta el Reglamento para el Cálculo de la Rentabilidad y el Riesgo de cada Fondo y del Mercado. 29 de Enero de 1999.

República de Venezuela. Gaceta Oficial Extraordinario No. 5.301. Decreto No. 3.263 mediante el cual se dicta el Reglamento sobre la Adecuación Patrimonial y Encaje de las Administradoras de los Fondos de Pensiones. 29 de Enero de 1999.

República de Venezuela. Gaceta Oficial Extraordinario No. 5.301. Decreto No. 3264 mediante el cual se dicta el Reglamento Parcial del Decreto Ley de Subsistema de Pensiones que regula el Derecho a la Información de los Afiliados ante las Administradoras de los Fondos de Pensiones. 29 de Enero de 1999. 